\title{
Eriocalyxin B blocks human SW1116 colon cancer cell proliferation, migration, invasion, cell cycle progression and angiogenesis via the JAK2/STAT3 signaling pathway
}

\author{
YUN-MIN LU, WEI CHEN, JIN-SHUI ZHU, WEI-XIONG CHEN and NI-WEI CHEN \\ Department of Gastroenterology, Shanghai Jiao Tong University Affiliated Sixth People's Hospital, \\ Shanghai 200233, P.R. China
}

Received October 24, 2014; Accepted September 16, 2015

DOI: $10.3892 / \mathrm{mmr} .2016 .4800$

\begin{abstract}
Eriocalyxin B, a natural ent-kaurene diterpene compound, has been shown to prevent carcinogenesis and tumor development. However, little is known regarding the mechanism underlying the antitumor activity of Eriocalyxin B in human colon cancer. The aim of the present study was to examine the role of Eriocalyxin B in SW1116 cells, and to verify the hypothesis that the Janus kinase 2 (JAK2)/signal transducer and activator of transcription 3 (STAT3) signaling pathway may serve as a therapeutic target in human colon cancer treatment. Cell proliferation was measured with a Cell Counting kit- 8 assay, and the cell cycle was assessed by flow cytometry. Cell migration and invasion were measured by Transwell analysis. In addition, western blot analysis was performed to detect the protein expression levels in SW1116 cells treated with various concentrations of Eriocalyxin B. The results demonstrated that $1 \mu \mathrm{mol} / 1$ Eriocalyxin B was effective at inhibiting JAK2 and STAT3 phosphorylation, followed by the downregulation of JAK2 and STAT3 downstream target expression, which resulted in the inhibition of cell proliferation, migration, invasion and angiogenesis. Eriocalyxin B also suppressed the expression of proliferation-associated protein (proliferating cell nuclear antigen) and angiogenesis-associated proteins (vascular endothelial growth factor and vascular endothelial growth factor receptor 2), as well as that of migration- and invasion-associated proteins (matrix metalloproteinase 2 and 9). These results suggested that Eriocalyxin B may suppress JAK2/STAT3 signaling, and thus act as a therapeutic or preventive agent in the treatment of human colon cancer.
\end{abstract}

Correspondence to: Dr Wei Chen, Department of Gastroenterology, Shanghai Jiao Tong University Affiliated Sixth People's Hospital, 600 Yishang Road, Xuhui, Shanghai 200233, P.R. China

E-mail: weichenwz@126.com

Key words: Eriocalyxin B, human colon cancer, SW1116 cells, Janus kinase 2, signal transducer and activator of transcription 3

\section{Introduction}

Signal transducer and activator of transcription 3 (STAT3) protein is a member of the STAT protein family. It acts as a cytoplasmic transcription factor and is phosphorylated by cytokines and growth factors, which results in its translocation from the cell surface to the nucleus. Ligand-bound cell surface receptors regulate tyrosine phosphorylation of the STAT3 protein through Janus kinase (JAK) and growth factor receptor tyrosine kinases (1). This process is rapid and transient during STAT3 protein activation in normal cells. However, abnormalities in the JAK/STAT signaling pathways have been demonstrated to be involved in the development and progression of several types of cancer $(2,3)$.

STAT3 activation is observed in the majority of human colon cancer cell lines $(4,5)$. However, the mechanisms underlying dysregulated STAT3 signaling initiation in the progression of human colon cancer have yet to be elucidated. STAT3 is known to promote the progression of cancer following activation by various pathways; however, a tumor suppressive role of STAT3 has recently been demonstrated, depending on the mutational background of the tumor $(6,7)$. Colon cancer is the sixth most common cancer type and the fifth leading cause of cancer-associated mortality in China (8). Since dietary characteristics have changed in recent years, the mortality associated with colon cancer has been estimated to be 608,000 people per year worldwide (9). However, early screening, diagnosis and development of chemotherapy may not be feasible in elderly patients with human colon cancer with a poor prognosis, due to its high toxicity and adverse reactions. Therefore, it is necessary to identify novel treatment agents with less severe side effects.

Numerous drugs used worldwide are extracted from natural plant species, and are used for the clinical treatment of patients with cancer $(10,11)$. Eriocalyxin B is a natural ent-kaurene diterpenoid compound extracted from Isodon eriocalyx var. laxiflora, a herb of the Labiatae family, distributed throughout Southwest China. It is reported to exhibit anti-inflammatory and antibacterial functions in local folk medicine, by modulating a variety of biological progresses via multiple signaling pathways $(11,12)$. Furthermore, Eriocalyxin B inhibited proliferation and induced apoptosis in several types of cancer cells, 
including ovarian cancer (13), pancreatic adenocarcinoma (14) and leukemia (15) cells. Eriocalyxin B was observed to arrest the cell cycle, induce apoptosis, and inhibit cancer invasion. However, the mechanisms underlying these anticancer effects remain under investigation. The present study aimed to investigate the molecular mechanisms underlying Eriocalyxin B induction of apoptosis and migration inhibition, as well as invasion in SW1116 human colon cancer cell lines.

\section{Materials and methods}

Reagents. Eriocalyxin B was purchased from BioBioPha Co., Ltd. (Kunming, China). Fetal bovine serum was purchased from Hangzhou Sijiqing Biological Engineering Materials Co., Ltd. (Hangzhou, China), and Dulbecco's modified Eagle's medium and propidium iodide (PI) were purchased from Sigma-Aldrich (St. Louis, USA). Primary antibodies targeting STAT3 (rabbit polyclonal; cat. no. ab119352; 1:1,000), phosphorylated (p)-STAT3 (rabbit polyclonal; cat. no. ab76315; 1:1,000, vascular endothelial growth factor (VEGF; mouse polyclonal; cat. no. ab68334; 1:200), vascular endothelial growth factor receptor 2 (VEGFR2; rabbit monoclonal; cat. no. ab131441; 1:500), proliferating cell nuclear antigen (PCNA; mouse polyclonal; cat. no. ab92552; 1:5,000), matrix metalloproteinase (MMP)-2 (rabbit polyclonal; cat. no. ab110186; 1:1,000), and MMP-9 (mouse polyclonal; cat. no. ab119906; 1:500) were purchased from Abcam (Cambridge, MA, USA), and those targeting glyceraldehyde 3-phosphate dehydrogenase (GAPDH; rabbit monoclonal; cat. no. 5174; 1:1,500), JAK2 (rabbit monoclonal; cat. no. 3230; 1:1,000), and p-JAK2 (rabbit monoclonal; cat. no. 3776; 1:800), were purchased from Cell Signaling Technology, Inc. (Danvers, MA, USA). Horseradish peroxidase-conjugated goat anti-rabbit/anti-mouse secondary antibodies (cat nos. A0208 and A0216; 1:1,000) were purchased from Beyotime Institute of Biotechnology (Haimen, China).

Cell culture. Human SW1116 colon cancer cell lines were obtained from the Academia Sinica Cell Bank (Shanghai, China), and cultured to $80 \%$ confluence in low-glucose DMEM supplemented with $10 \%(\mathrm{v} / \mathrm{v})$ fetal bovine serum, $100 \mathrm{IU} / \mathrm{ml}$ penicillin and $10 \mathrm{mg} / \mathrm{ml}$ streptomycin (Invitrogen; Thermo Fisher Scientific, Inc., Waltham, MA, USA). The cell cultures were incubated in an atmosphere containing $5 \% \mathrm{CO}_{2}$ at $37^{\circ} \mathrm{C}$ for $72 \mathrm{~h}$.

Cell proliferation assay. The proliferative effects of Eriocalyxin B on the SW1116 cells were determined using a Cell Counting kit-8 assay (Dojindo Molecular Technologies, Inc., Rockville, MD, USA) as previously described (16). Briefly, the SW1116 cells in logarithmic growth-phase were harvested and cultured in 96-well plates in $100 \mu 1$ volumes. The cells were then treated with various concentrations $(0.2$, 0.5 and $1 \mu \mathrm{mol} / \mathrm{l}$ ) of Eriocalyxin B, and incubated for 0,6 , 12,24 and $48 \mathrm{~h}$ at $37^{\circ} \mathrm{C}$. Cells that were not treated with Eriocalyxin B served as a control group. Absorbance at a wavelength of $450 \mathrm{~nm}$ was measured using a Multiskan EX plate reader (Thermo Fisher Scientific, Inc.).

Cell cycle analysis by flow cytometry. For cell cycle analysis, the SW1116 cells were seeded in 12-well plates at a density

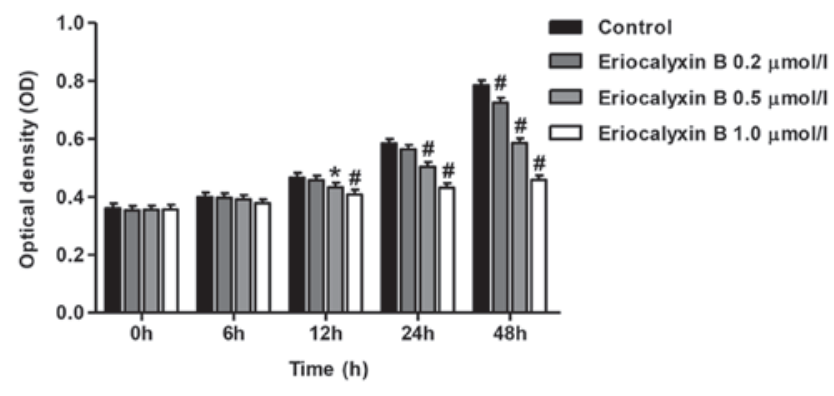

Figure 1. Eriocalyxin B inhibited the proliferation of SW1116 cells. The cells were treated with Eriocalyxin B $(0.2,0.5$ and $1 \mu \mathrm{mol} / 1)$ for $0,6,12,24$ or $48 \mathrm{~h}$, and cell proliferation was determined using a Cell Counting kit- 8 assay. Each bar represents the mean \pm standard deviation of three independent experiments. ${ }^{*} \mathrm{P}<0.05$ or ${ }^{\#} \mathrm{P}<0.01$, compared control.

of $1 \times 10^{3}$ cells/well, prior to being treated with various concentrations of Eriocalyxin B $(0.2,0.5$ and $1 \mu \mathrm{mol} / \mathrm{l})$ for $48 \mathrm{~h}$. Following treatment, the number of cells in the various phases of cell cycle was determined by PI staining, in order to ascertain the DNA content (17). Cells that were not treated with Eriocalyxin B served as a control group. Data acquisition was performed using an EPICSXLMCL flow cytometer (Beckman Coulter, Inc. Brea, CA, USA) using Cell Quest software BD Accuri C6 version 1.0.264.21 (BD Biosciences, Franklin Lakes, NJ, USA).

Migration and invasion assay. The migration and invasion of the SW1116 cells were measured using a Transwell assay as previously described (18). Briefly, Transwell membranes (Corning Incorporated, Corning, NY, USA) coated with or without Matrigel (BD Biosciences) were used to measure cell migration and invasion ability. The SW1116 cells were treated with various concentrations of Eriocalyxin B (0.2, 0.5 and $1 \mu \mathrm{mol} / 1)$. The chambers were subsequently placed in a $37^{\circ} \mathrm{C}$ incubator for $48 \mathrm{~h}$. The filters were fixed with $4 \%$ methanol and stained with $0.5 \%$ methylrosanilnium chloride solution (JRDUN Biotechnology Co., Ltd., Shanghai, China) for $30 \mathrm{~min}$. Untreated cells served as a control group. Evaluation of the number of migratory and invasive cells was performed under a microscope (x200; CX41RF; Olympus Corporation, Tokyo, Japan).

Western blot analysis. Following treatment with Eriocalyxin B at the desired concentrations for the appropriate times, the expression levels of proliferation proteins (PCNA), migration and invasion proteins (MMP-2 and MMP-9) and angiogenesis-associated proteins (VEGF and VEGFR2) were detected by western blotting according to the manufacturer's instructions. Cells untreated with Eriocalyxin B served as a control group. GAPDH antibody was used as an internal control. The experiment was repeated three times independently. Briefly, the SW1116 cell lysates were harvested and protein was extracted using radioimmunoprecipitation buffer (JRDUN Biotechnology Co., Ltd.). Total protein $(50 \mu \mathrm{g})$ was separated using 10 or 15\% SDS-PAGE (JRDUN Biotechnology Co., Ltd.) prior to being transferred to polyvinylidene difluoride membranes (Sigma-Aldrich). The membranes were blocked with fat-free milk for $1 \mathrm{~h}$ at room temperature $\left(25^{\circ} \mathrm{C}\right)$. The 


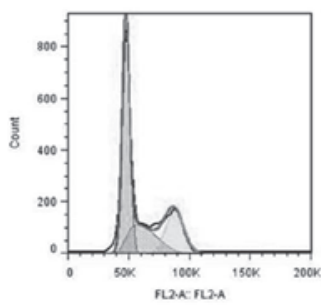

Control

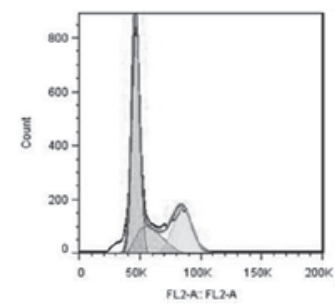

$0.2 \mu \mathrm{mol} / 1$

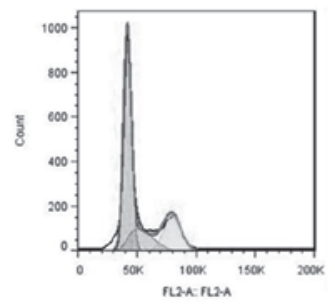

$0.5 \mu \mathrm{mol} / \mathrm{l}$

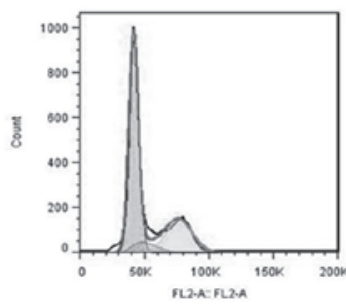

$1.0 \mu \mathrm{mol} / \mathrm{l}$

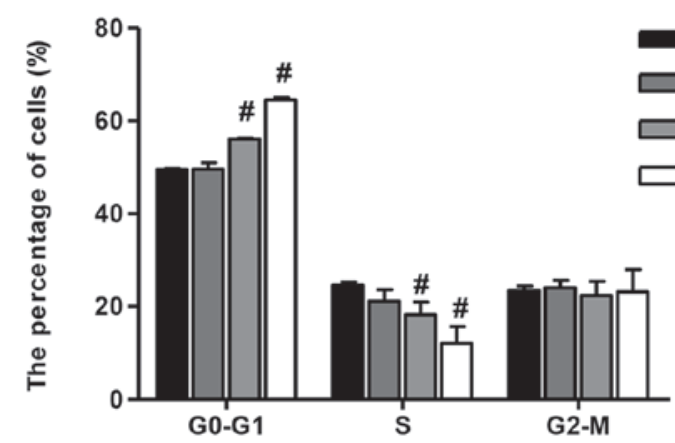

Figure 2. Eriocalyxin B arrests the cell cycle of SW1116 cells. The cells were treated with Eriocalyxin B $(0.2,0.5$ and $1 \mu$ mol/l) for $0,6,12,24$, or $48 \mathrm{~h}$, and the cell cycle was analyzed using a propidium iodide staining assay and flow cytometry. Each bar represents the mean \pm standard deviation of three independent experiments. " $\mathrm{P}<0.01$, compared with control cells.

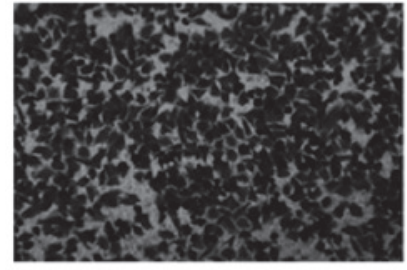

Control

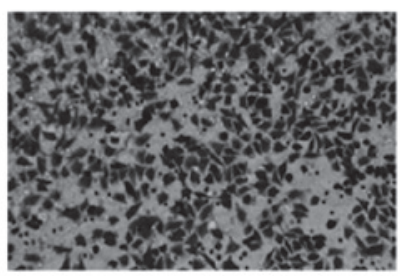

$0.5 \mu \mathrm{mol} / 1$

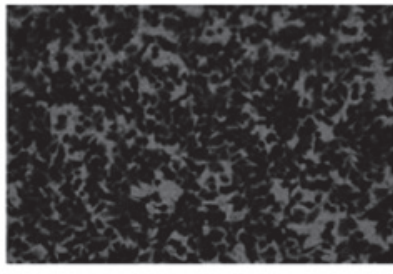

$0.2 \mu \mathrm{mol} / \mathrm{l}$

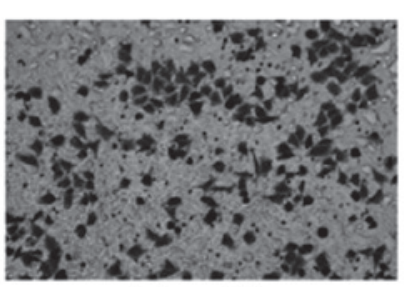

$1.0 \mu \mathrm{mol} / \mathrm{l}$

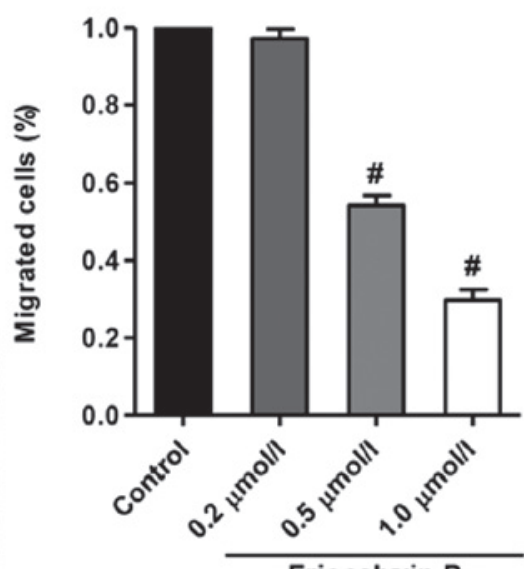

Eriocalyxin B

Figure 3. Eriocalyxin B inhibits SW1116 cell migration, as demonstrated by a Transwell migration assay. Following $48 \mathrm{~h}$ incubation with or without the indicated concentrations of Eriocalyxin B, the cells that migrated to the lower chamber were fixed, stained, and counted under light microscopy (x200). Random fields were scanned (four fields per filter of the well) for the presence of cells on the lower side of the membrane. Each bar represents the mean \pm standard deviation of three independent experiments. ${ }^{\#} \mathrm{P}<0.01$, compared with control cells.

membranes were subsequently incubated with the primary antibodies for $2 \mathrm{~h}$ at $25^{\circ} \mathrm{C}$, prior to being incubated with secondary antibodies for $1 \mathrm{~h}$ at $37^{\circ} \mathrm{C}$, and were subsequently washed three times with Tris-buffered saline with Tween 20. The blots were visualized using enhanced chemiluminescence (EMD Millipore, Billerica, MA, USA), and the signals were quantified by densitometry using Quantity One software version 4.62 (Bio-Rad Laboratories, Inc., Hercules, CA, USA).

Statistical analysis. The data are presented as the mean \pm standard deviation. One-way analysis of variance followed by
Dunnett's test was used to analyze significant differences between results. Statistical analyses were performed using GraphPad Prism 5 software (GraphPad Software, Inc., La Jolla, CA, USA). $\mathrm{P}<0.05$ was considered to indicate a statistically significant difference.

\section{Results}

Eriocalyxin B inhibits the proliferation of SW1116 cells. SW1116 cells were serum-starved overnight and subsequently cultured with or without various concentrations of Eriocalyxin B for 0, 6, 12, 24 and 48 h. Eriocalyxin B inhibited 


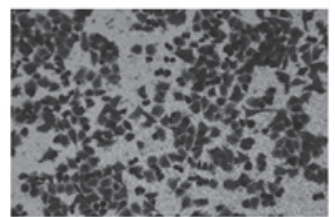

Control

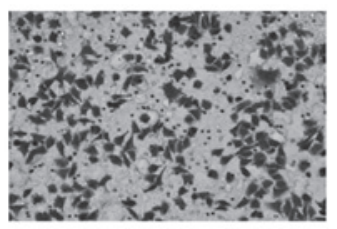

$0.5 \mu \mathrm{mol} / \mathrm{I}$

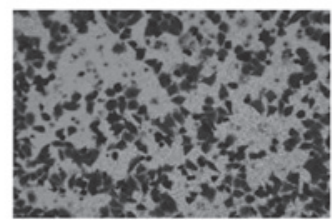

$0.2 \mu \mathrm{mol} / \mathrm{l}$

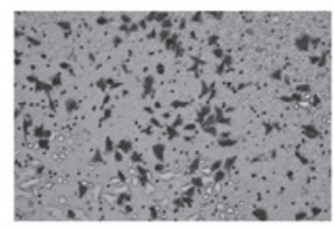

$1.0 \mu \mathrm{mol} / \mathrm{I}$

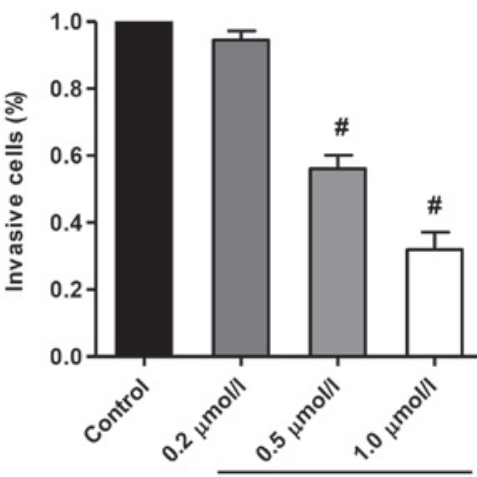

Eriocalyxin B

Figure 4. Eriocalyxin B inhibits SW1116 cell invasion, as demonstrated by a Matrigel invasion assay. SW1116 cells in serum-free medium with or without Eriocalyxin B were seeded into the upper chamber of the Transwell system. The bottom well was filled with Dulbecco's modified Eagle's medium with $10 \%$ fetal bovine serum. Following $48 \mathrm{~h}$ incubation, the cells that had invaded through the Matrigel membrane were stained with $0.5 \%$ methylrosanilnium chloride solution, and counted under a light microscope (x200). The experiments were performed three times in triplicate. Each bar represents the mean \pm standard deviation of three independent experiments. ${ }^{\#} \mathrm{P}<0.01$, compared with control cells.

A
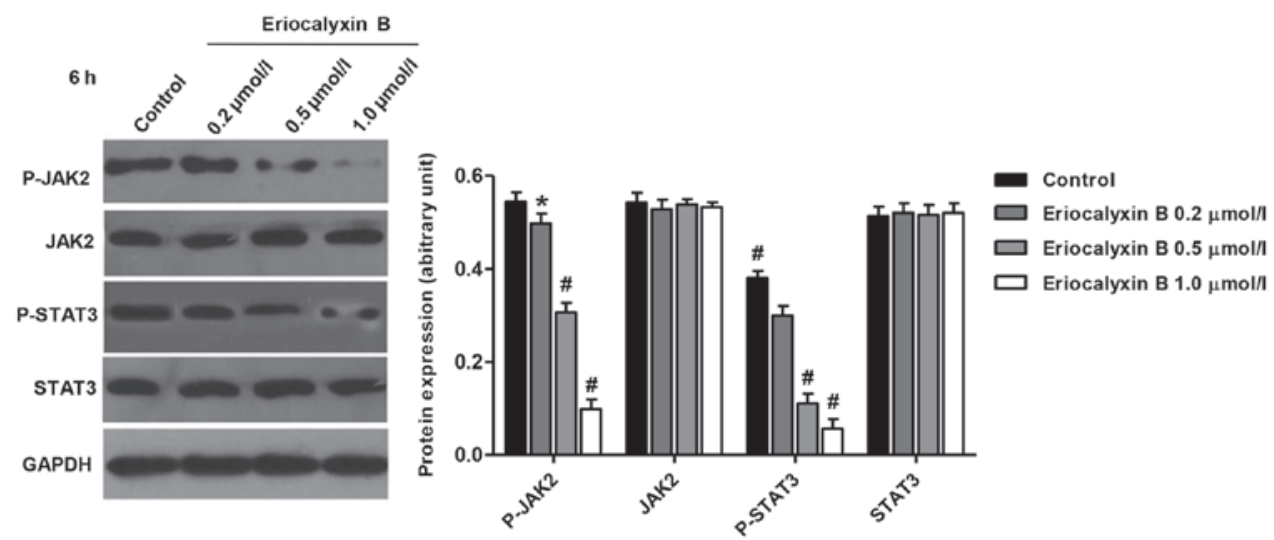

B
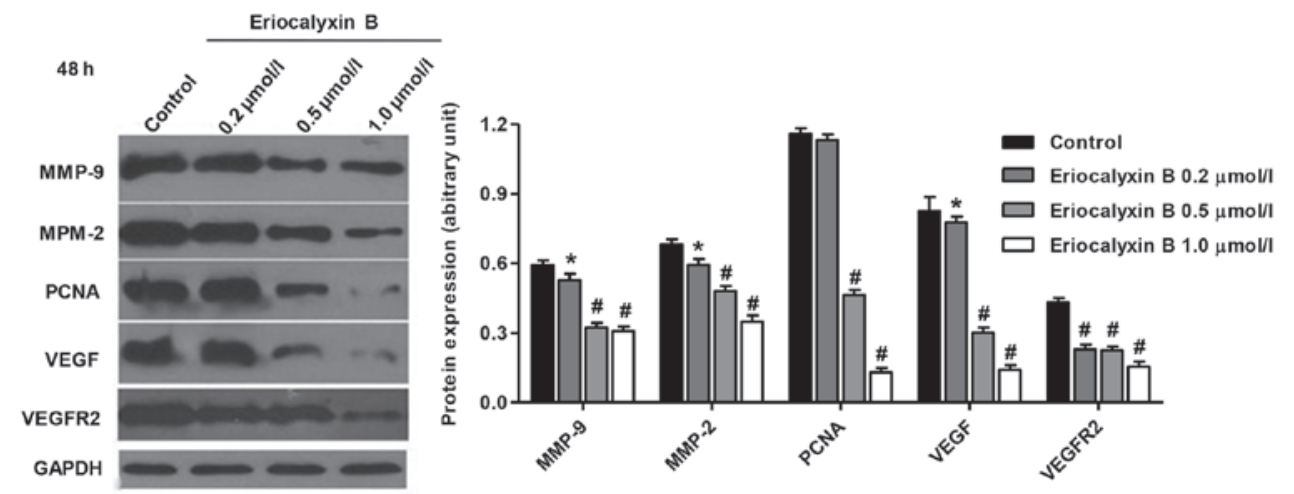

Figure 5. Effects of Eriocalyxin B treatment on the protein expression levels of p-JAK2, p-STAT3, MMP-2, MMP-9, PCNA, VEGF and VEGFR2. (A) The SW1116 cells were treated with various concentrations of Eriocalyxin B for $6 \mathrm{~h}$ and (B) $48 \mathrm{~h}$. The protein expression levels were quantified by western blotting. Equal quantities of total cellular protein $(20 \mu \mathrm{g})$ were separated by $10-15 \%$ SDS-PAGE and GAPDH was used as a loading control. Each bar represents the mean \pm standard deviation of three independent experiments. ${ }^{*} \mathrm{P}<0.05$ and ${ }^{\#} \mathrm{P}<0.01$, compared with control cells. p, phosphorylated; JAK2, Janus kinase 2 ; STAT3, signal transducer and activator of transcription 3; MMP, matrix metalloproteinase; PCNA, proliferating cell nuclear antigen; VEGF, vascular endothelial growth factor 2; VEGFR2, vascular endothelial growth factor receptor 2; GAPDH, glyceraldehyde 3-phosphate dehydrogenase.

the proliferation of SW1116 cells in a time- and dose-dependent manner. Following initial experimentation, Eriocalyxin B at dose of $1 \mu \mathrm{mol} / \mathrm{l}$ significantly inhibited cell proliferation, compared with Eriocalyxin B at dose of $0.2 \mu \mathrm{mol} / 1$, and significant differences in cell proliferation occurred between 0.2 , 0.5 and $1 \mu \mathrm{mol} / \mathrm{l}$ concentrations at $48 \mathrm{~h}(\mathrm{P}<0.05$ and $\mathrm{P}<0.01$; Fig. 1).
Eriocalyxin B arrests the cell cycle of SW1116 cells. The cell cycle distribution of SW1116 cells was analyzed by flow cytometry following $48 \mathrm{~h}$ exposure to Eriocalyxin B at various concentrations $(0.2,0.5$ and $1 \mu \mathrm{mol} / \mathrm{l})$. The number of cells in the $\mathrm{G}_{0}-\mathrm{G}_{1}$ phase following Eriocalyxin $B$ treatment increased to $64.49 \%$ following $48 \mathrm{~h}$ of incubation. The number of cells in the $\mathrm{S}$ phase decreased to $12.13 \%$ following $48 \mathrm{~h}$ of incubation. 
In the control group, the number of cells in the $\mathrm{G}_{0}-\mathrm{G}_{1}$ and $\mathrm{S}$ phase were 49.57 and $24.58 \%$, respectively (Fig. 2). No significant difference was observed in the number of cells in the $\mathrm{G}_{2}-\mathrm{M}$ phase.

Eriocalyxin B inhibits the migration of SW1116 cells. The migratory inhibition of SW1116 cells by Eriocalyxin B was analyzed using a Transwell assay, the results of which are presented in Fig. 3. Eriocalyxin B significantly inhibited SW1116 cell migration; however, this effect was not observed at $0.2 \mu \mathrm{mol} / 1$ Eriocalyxin $\mathrm{B}(\mathrm{P}<0.01)$.

Eriocalyxin B inhibits the invasion of SW1116 cells. The invasion inhibition of the SW1116 cells by Eriocalyxin B was measured using a Matrigel-based Transwell assay, and the results are presented in Fig. 4. Eriocalyxin B significantly inhibited SW1116 cell invasion $(\mathrm{P}<0.01)$, however the effect of Eriocalyxin B at $0.2 \mu \mathrm{mol} / 1$ was not observed. These results clearly suggest that Eriocalyxin B targets SW1116 cells by exhibiting antimigratory and anti-invasive effects.

Eriocalyxin B effects the expression levels of SW1116 cell proteins. The effects of Eriocalyxin B on the JAK2/STAT3 signaling pathway and tumorigenesis-associated proteins in the SW1116 cells following treatment with Eriocalyxin B were determined by western blotting. Eriocalyxin B inhibited the expression levels of p-JAK2 and p-STAT3 in SW1116 cells $(\mathrm{P}<0.05$ and $\mathrm{P}<0.01$; Fig. 5A), however the expression levels of JAK2 and STAT3 remained unaltered by Eriocalyxin B treatment. The expression levels of MMP9, MMP2, PCNA, VEGF and VEGFR2 were significantly decreased, as compared with the corresponding control groups $(\mathrm{P}<0.05$ and $\mathrm{P}<0.01$; Fig. 5B). These effects may result in the inhibition of proliferation, migration, invasion and angiogenesis in SW1116 cells following exposure to $1 \mu \mathrm{mol} / 1$ Eriocalyxin B.

\section{Discussion}

Human colon cancer is the fourth most common type of cancer in men and, the third most common in women worldwide, accounting for $\sim 8 \%$ of all cancer-associated mortality $(19,20)$. To date, to the best of our knowledge, no study has explored the effects of Eriocalyxin B on the development and progression of human colon cancer. Several studies have reported that modulation of constitutive JAK2/STAT3 activity via genetic and pharmacological approaches, demonstrated the role of abnormal activity of JAK2/STAT3 in malignant transformation and tumor progression, and thus suggested that JAK2/STAT3 may serve as a novel cancer drug target $(21,22)$.

Eriocalyxin B suppressed cell proliferation, invasion, metastasis, and angiogenesis through a mechanism that has yet to be fully elucidated (23-25). Numerous genes regulated by signal transducers and transcription activators were involved in these processes, therefore it was hypothesized that Eriocalyxin B functions in human colon cancer by modulating JAK2/STAT3 activation. The present study demonstrated that Eriocalyxin B inhibited SW1116 cell proliferation by inhibiting the cell cycle at the $\mathrm{G}_{0}-\mathrm{G}_{1}$ phase and decreasing the number of cells in the $\mathrm{S}$ phase. In addition, no significant differences were observed in the number of cells in the $\mathrm{G}_{2}-\mathrm{M}$ phases. Furthermore, the protein expression levels of PCNA were significantly downregulated following SW1116 cell treatment with various concentrations of Eriocalyxin B for $48 \mathrm{~h}$. PCNA is overexpressed in numerous types of tumor regulated by STAT3, and is required for cells to proliferate (26).

The findings of the present study demonstrated that Eriocalyxin B inhibited SW1116 cell migratory and invasive abilities, predominantly via the downregulation of gene product expression, specifically of genes involved in cell migration, invasion and angiogenesis, such as MMP-2, MMP-9, VEGF and VEGFR2, which are regulated by STAT3. MMP-2 and MMP-9 have important roles in human colon cancer progression, tumor migration, invasion and angiogenesis (27). A previous study reported that the upregulation of MMP-2 and MMP-9 expression is associated with poor survival prognosis in patients with human colon cancer, which resulted from degradation of the extracellular matrix, and induction of cell metastasis (28). Angiogenesis is critical for cancer growth and progression. VEGF is a potent angiogenic growth factor in human colon cancer, and inhibition of VEGF resulted in inhibition of angiogenesis and cancer growth (29). VEGFR2 activation is closely associated with tumor- and vessel-mediated processes in human colon cancer, and is responsible for tumor survival, as well as tumor growth and metastasis (30).

To further investigate the mechanism underlying Eriocalyxin B-induced JAK2/STAT3 signaling inhibition in SW1116 cells, the present study further examined the proteins upstream of STAT3. JAK2 is considered to be associated with STAT3 activation. Phosphorylation of JAK2 was suppressed by treatment with Eriocalyxin B in the SW1116 cells. These results suggested that Eriocalyxin B exerts its inhibitory effects on STAT3 activation by inhibiting the activation of JAK2. Activation of the STAT3 signaling pathway has been observed in numerous patients with cancer (31). Upregulated levels of p-STAT3 expression is associated with poor survival rates in patients with colon (32), breast (33) and gastric cancer (34). A previous study reported a correlation between STAT3 pathway activation and high clinicopathological grade with advanced stage in a variety of cancer types (35). These results suggest that the JAK2/STAT3 signaling pathway may function as a therapeutic target and a prognostic marker in patients with colon cancer (36).

In conclusion, to the best of our knowledge, prior to the present study no research had been conducted on the role of Eriocalyxin B in SW1116 human colon cancer cells, nor its JAK2/STAT3 signaling protein targets. The present study therefore reports for the first time the anticancer mechanism underlying the effects of Eriocalyxin B in SW1116 cell tumorigenesis and colon cancer progression. It was demonstrated that this predominantly occurred by inhibiting the activation of the JAK2/STAT3 signaling pathway. Therefore, the JAK2/STAT3 signaling pathway has a significant role in human colon cancer oncogenesis, and may serve as a potential therapeutic target for human colon cancer treatment.

\section{Acknowledgements}

The present study was supported by the Doctoral Innovation Fund Projects from Shanghai Jiao Tong University School of Medicine (no. BXJ201437). 


\section{References}

1. Hedvat M, Huszar D, Herrmann A, Gozgit JM, Schroeder A, Sheehy A, Buettner R, Proia D, Kowolik CM, Xin H, et al: The JAK2 inhibitor AZD1480 potently blocks Stat3 signaling and oncogenesis in solid tumors. Cancer Cell 16: 487-497, 2009.

2. Huang S: Regulation of metastases by signal transducer and activator of transcription 3 signaling pathway: Clinical implications. Clin Cancer Res 13: 1362-1366, 2007.

3. Koppikar P, Lui VW, Man D, Xi S, Chai RL, Nelson E, Tobey AB and Grandis JR: Constitutive activation of signal transducer and activator of transcription 5 contributes to tumor growth, epithelial-mesenchymal transition and resistance to epidermal growth factor receptor targeting. Clin Cancer Res 14: 7682-7690, 2008.

4. Park KW, Kundu J, Chae IG, Kim DH, Yu MH, Kundu JK and Chun KS: Carnosol induces apoptosis through generation of ROS and inactivation of STAT3 signaling in human colon cancer HCT116 cells. Int J Oncol 44: 1309-1315, 2014.

5. Shen A, Chen Y, Hong F, Lin J, Wei L, Hong Z, Sferra TJ and Peng J: Pien Tze Huang suppresses IL-6-inducible STAT3 activation in human colon carcinoma cells through induction of SOCS3. Oncol Rep 28: 2125-2130, 2012.

6. Lee J, Kim JC, Lee SE, Quinley C, Kim H, Herdman S, Corr M and Raz E: Signal transducer and activator of transcription 3 (STAT3) protein suppresses adenoma-to-carcinoma transition in Apcmin/+ mice via regulation of Snail-1 (SNAI) protein stability. J Biol Chem 287: 18182-18189, 2012.

7. Musteanu M, Blaas L, Mair M, Schlederer M, Bilban M, Tauber S, Esterbauer H, Mueller M, Casanova E, Kenner L, et al: Stat3 is a negative regulator of intestinal tumor progression in Apc min mice. Gastroenterology 138: 1003-1011, 2010.

8. Chen W, Zheng R, Zhang S, Zhao P, Zeng H, Zou X and He J: Annual report on status of cancer in China, 2010. Chin J Cancer Res 26: 48-58, 2014

9. Marisa L, de Reyniès A, Duval A, Selves J, Gaub MP, Vescovo L, Etienne-Grimaldi MC, Schiappa R, Guenot D, Ayadi M, et al: Gene expression classification of colon cancer into molecular subtypes: Characterization, validation, and prognostic value. PloS Med 10: e1001453, 2013.

10. Jiang R, Wang H, Deng L, Hou J, Shi R, Yao M, Gao Y, Yao A, Wang X, Yu L and Sun B: IL-22 is related to development of human colon cancer by activation of STAT3. BMC Cancer 13: 59, 2013.

11. Ikezoe T, Chen SS, Tong XJ, Heber D, Taguchi $\mathrm{H}$ and Koeffler HP: Oridonin induces growth inhibition and apoptosis of a variety of human cancer cells. Int J Oncol 23: 1187-1193, 2003.

12. Wang L, Zhao WL, Yan JS, Liu P, Sun HP, Zhou GB, Weng ZY, Wu WL, Weng XQ and Sun XJ: Eriocalyxin B induces apoptosis of $t(8 ; 21)$ leukemia cells through NF-kappaB and MAPK signaling pathways and triggers degradation of AML1-ETO oncoprotein in a caspase-3-dependent manner. Cell Death Differ 14: 306-317, 2007.

13. Leizer AL, Alvero AB, Fu HH, Holmberg JC, Cheng YC, Silasi DA, Rutherford T and Mor G: Regulation of inflammation by the NF- $\kappa$ B pathway in ovarian cancer stem cells. Am J Reprod Immunol 65: 438-447, 2011.

14. Li L, Yue GG, Lau CB, Sun H, Fung KP, Leung PC, Han Q and Leung PS: Eriocalyxin B induces apoptosis and cell cycle arrest in pancreatic adenocarcinoma cells through caspase- and p53-dependent pathways. Toxicol Appl Pharmacol 262: 80-90, 2012.

15. Zhang YW, Jiang XX, Chen QS, Shi WY, Wang L, Sun HD, Shen ZX, Chen Z, Chen SJ and Zhao WL: Eriocalyxin B induces apoptosis in lymphoma cells through multiple cellular signaling pathways. Exp Hematol 38: 191-201, 2010.

16. Takaishi S, Okumura T, Tu S, Wang SS, Shibata W, Vigneshwaran R, Gordon SA, Shimada Y and Wang TC: Identification of gastric cancer stem cells using the cell surface marker CD44. Stem Cells 27: 1006-1020, 2009.

17. Lin SY, Lai WW, Chou CC, Kuo HM, Li TM, Chung JG and Yang JH: Sodium ascorbate inhibits growth via the induction of cell cycle arrest and apoptosis in human malignant melanoma A375.S2 cells. Melanoma Res 16: 509-519, 2006.

18. Chen HW, Yu SL, Chen JJ, Li HN, Lin YC, Yao PL, Chou HY, Chien CT, Chen WJ, Lee YT and Yang PC: Anti-invasive gene expression profile of curcumin in lung adenocarcinoma based on a high throughput microarray analysis. Mol Pharmacol 65: 99-110, 2004.
19. Kamangar F, Dores GM and Anderson WF: Patterns of cancer incidence, mortality and prevalence across five continents: Defining priorities to reduce cancer disparities in different geographic regions of the world. J Clin Oncol 24: 2137-2150, 2006.

20. Moghimi-Dehkordi B and Safaee A: An overview of colorectal cancer survival rates and prognosis in Asia. World J Gastrointest Oncol 4: 71-75, 2012

21. Frank DA: STAT3 as a central mediator of neoplastic cellular transformation. Cancer Lett 251: 199-210, 2007.

22. Rivat C, Rodrigues S, Bruyneel E, Piétu G, Robert A, Redeuilh G, Bracke M, Gespach C and Attoub S: Implication of STAT3 signaling in human colonic cancer cells during intestinal trefoil factor 3 (TFF3)- and vascular endothelial growth factor-mediated cellular invasion and tumor growth. Cancer Res 65: 195-202, 2005.

23. Lu Y, Chen B, Song JH, Zhen T, Wang BY, Li X, Liu P, Yang X, Zhang QL, Xi XD, et al: Eriocalyxin B ameliorates experimental autoimmune encephalomyelitis by suppressing Th1 and Th17 cells. Proc Natl Acad Sci USA 110: 2258-2263, 2013.

24. Leung CH, Grill SP, Lam W, Gao W, Sun HD and Cheng YC: Eriocalyxin B inhibits nuclear factor-kappaB activation by interfering with the binding of both p65 and p50 to the response element in a noncompetitive manner. Mol Pharmacol 70: 1946-1955, 2006.

25. Coupland VH, Lagergren J, Lüchtenborg M, Jack RH, Allum W, Holmberg L, Hanna GB, Pearce N and Møller H: Hospital volume, proportion resected and mortality from oesophageal and gastric cancer: A population-based study in England, 20042008. Gut 62: 961-966, 2013

26. Camargo MC, Kim WH, Chiaravalli AM, Kim KM, Corvalan AH, Matsuo K, Yu J, Sung JJ, Herrera-Goepfert R, Meneses-Gonzalez F, et al: Improved survival of gastric cancer with tumour Epstein-Barr virus positivity: An international pooled analysis. Gut 63: 236-243, 2014.

27. Zucker S and Vacirca J: Role of matrix metalloproteinases (MMPs) in colorectal cancer. Cancer Metastasis Rev 23: 101-117, 2004

28. Langers A, Verspaget H, Hawinkels L, Kubben FJ, van Duijn W, van der Reijden JJ, Hardwick JC, Hommes DW and Sier CF: MMP-2 and MMP-9 in normal mucosa are independently associated with outcome of colorectal cancer patients. Brit J Cancer 106: 1495-1498, 2012.

29. Ahluwalia A, Jones MK, Matysiak-Budnik T and Tarnawski AS: VEGF and colon cancer growth beyond angiogenesis: Does VEGF directly mediate colon cancer growth via a nonangiogenic mechanism? Curr Pharm Design 20: 1041-1044, 2014.

30. Jayasinghe C, Simiantonaki N, Habedank S and Kirkpatrick CJ: The relevance of cell type-and tumor zone-specific VEGFR-2 activation in locally advanced colon cancer. J Exp Clin Cancer Res 34: 42, 2015.

31. Kim JE, Patel M, Ruzevick J, Jackson CM and Lim M: STAT3 activation in glioblastoma: Biochemical and therapeutic implications. Cancers (Basel) 6: 376-395, 2014.

32. Cross-Knorr S, Lu S, Perez K, Guevara S, Brilliant K, Pisano C, Quesenberry PJ, Resnick MB and Chatterjee D: RKIP phosphorylation and STAT3 activation is inhibited by oxaliplatin and camptothecin and are associated with poor prognosis in stage II colon cancer patients. BMC Cancer 13: 463, 2013.

33. Dave B, Landis MD, Tweardy D, Chang JC, Dobrolecki LE, Wu MF, Zhang X, Westbrook TF, Hilsenbeck SG, Liu D and Lewis MT: Selective small molecule Stat 3 inhibitor reduces breast cancer tumor-initiating cells and improves recurrence free survival in a human-xenograft model. PloS One 7: e30207, 2012.

34. Xiong H, Du W, Wang JL, Wang YC, Tang JT, Hong J and Fang JY: Constitutive activation of STAT3 is predictive of poor prognosis in human gastric cancer. J Mol Med (Berl) 90: 1037-1046, 2012.

35. Lo HW, Cao X, Zhu H and Ali-Osman F: Constitutively activated STAT3 frequently coexpresses with epidermal growth factor receptor in high-grade gliomas and targeting STAT3 sensitizes them to Iressa and alkylators. Clin Cancer Res 14: 6042-6054, 2008.

36. Fletcher S, Turkson J and Gunning PT: Molecular approaches towards the inhibition of the signal transducer and activator of transcription 3 (Stat3) protein. ChemMedChem 3: 1159-1168, 2008 . 